\title{
Mathematical Patterns: It's Impact on Students' Performance in College Algebra
}

\author{
Christina V. Maglipong ${ }^{1}$, Jean L. Bongolto ${ }^{2}$ \\ ${ }^{1}$ University of Science and Technology of Southern Philippines, Lapasan Highway, Cagayan de Oro City, Philippines \\ ${ }^{2}$ St. Rita's College of Balingasag, Balingasag, Misamis Oriental, Philippines
}

\begin{abstract}
The purpose of this study was to determine the influence of mathematical patterns on the student's performance in terms of conceptual understanding and achievement in college algebra and their perception towards the use of mathematical patterns. The study used the pretest-posttest quasi-experimental-control group design. Two sections were randomly chosen from the five sections that were officially enrolled in the first semester of school year 2014-2015. One group was randomly assigned as the control group and the second one as the experimental group. The control group had undergone the lecture-discussion while the experimental group underwent mathematical patterns. The study used three instruments: Mathematics Achievement and Conceptual Understanding Tests and the Interview Guide Questions. The performance of both groups of the students in the pretest and posttest were described in terms of the mean and standard deviation. The analysis of covariance (ANCOVA) was used to determine the effect of two teaching methods. Based on the analysis of the study, the results revealed that there was a significant difference in the student's achievements and conceptual understanding scores as influenced by the teaching method which is the use of mathematical patterns. Furthermore, he students in the experimental group expressed that mathematical patterns was enjoyable and interesting because it allowed them to develop their critical thinking and made mathematics learning easier for them. Based on the findings of the study, the researcher concluded that the use of mathematical patterns is an effective method of teaching in improving students' achievement and conceptual understanding. The researcher recommends that mathematical patterns may be used by mathematics teachers in their classes to help improve achievement and develop conceptual understanding even to pre-school, elementary and secondary levels.
\end{abstract}

Keywords: mathematical patterns

\section{Introduction}

Many students at the present are unable to continue college education after completing high school due to financial instability, early marriage and other family issues. Based on the initial investigation and interviews, many of the students who are enrolled in St. Rita's College of Balingasag come from the colleges and universities of Cagayan de Oro City, citing financial constraints as one of the major reasons for this move. In addition, the students' profile show that some are drop outs, transferees and some have started college education late due to the same reason mentioned earlier.

Learning mathematics requires a continuous process of acquisition of knowledge and critical thinking skills. Knowing the present set of students, acquisition of mathematical concept may be interesting and enjoyable if done through investigation of patterns that requires them to think deeply and critically for better conceptual understanding. This is necessary because of the abstract nature of mathematics.

The patterns studied by mathematicians are for all practical purposes and as real as atomic particles studied by physicist (Fi, Degner, 2012). Pattern recognition is a critical component of success in mathematics. Students at all levels may be provided with opportunities to investigate and uncover patterns throughout their mathematical careers to allow them to explore situations because pattern recognition plays a vital role in the construction of important mathematical model (Quinn, 2005). of mathematical ideas which involves observation, representation and investigation of arrangements and relationships in social and physical phenomena and between mathematical objects themselves (Waters, 2004; English, 2004). It is essential for students to learn the nature of mathematical patterns for the development of spatial awareness, sequencing and ordering, comparison and classification of ideas. Thus, the development of pattern based thinking, the use of patterns to analyze and solve problems is an extremely powerful tool for doing and understanding mathematics.

In addition, the world trend for quality instruction is increasing because of global competitiveness. This requires high cognitive demand mathematics instruction because the National Mathematics Advisory Panel (2008) has noted that the differences in instruction lead to significant differences in student's achievement. Thus, the importance of high quality instruction that model a critical thinking classroom learning process is very necessary. The high cognitive demand instruction requires teachers who could design a comprehensive and engaging teaching - learning environment which uses effective visuals to help learners with a wide variety of learning styles to develop a strong conceptual understanding of mathematical concepts (Galvez, 2009) through patterns.

The use of patterns have shown promising effect on students' achievement which challenge the researcher if it will work among college students in St. Rita's College of Balingasag, hence, this research.

Moreover, the use of patterns is important in the abstraction

Volume 6 Issue 1, January 2017

www.ijsr.net

Licensed Under Creative Commons Attribution CC BY 


\section{International Journal of Science and Research (IJSR) \\ ISSN (Online): 2319-7064}

Index Copernicus Value (2015): 78.96 | Impact Factor (2015): 6.391

\section{Literature Review}

\section{Mathematical Patterns}

The Open University (1988) website stated that imagery is a powerful force for perception and understanding. Being able to "see" something mentally is a common metaphor for understanding it. An image may be of some geometrical shape, or of a graph or diagram, or it may be some set of symbols or some procedures. This means that if you really want to grasp a concept or idea, struggling to visualize is worthwhile. Diagrams or symbols on paper, or physical apparatus are of help. Image of geometrical shape among mathematical models use patterns. The geometric setting for many pattern problems is a sequence of two-dimensional shapes, which is ideally suited to support the recognition of algebraic patterns. Thus, geometric problems help students progress from predicting numerical patterns to expressing algebraic generalizations (Beigie, 2011).

Witzel (2003) and his colleagues conducted a study on students identified as having difficulty in learning algebra. The study found out that student who learned how to solve algebra transformation equations through concrete - pictorial approach (CPA) scored higher on post instruction and follow-uptests than the control peers receiving traditional instruction. Furthermore, students who used the concretepictorial approach sequence of instruction performed fewer procedural errors when solving for algebraic variables. This study has bearing with patterns.

Thornton (2001) points three reasons to re-evaluate the role of visualization in school mathematics: (1) mathematics is currently identified with the study of patterns; (2) visualization can often provide simple and powerful approaches to problem solving; and (3) teachers should recognize the importance of helping students develop a repertoire of techniques to approach mathematical situations.

Schulz (2011) said that students need to understand patterns, relation and functions to form mathematics concept. They should know how to analyze mathematical situations and structures using symbols; mathematical models to represents and understand quantitative relationships and analyze change in various contexts. A strong foundation in algebra is deemed necessary in the high school level and it is an important indicator in determining the readiness of students; however, the present study did not only consider patterns in algebra, but also other areas of mathematics like geometry. Furthermore, Vinogradova (2010) added that geometry can be used to help students visualize and better understand broad range of mathematical concepts through patterns.

Beigie (2011) found out in his study on the leap of patterns that geometric counting problems offer students a concrete and pictorial setting to follow the abstraction process from number patterns to algebraic expressions. It also allows them to solve problems because the underlying geometry is assisting the algebraic steps. He added that pattern recognition through counting lies at the foundational heart of algebraic thinking and geometric measurement and connects the two topics in a way that reinforces one another.

Latonio (2006) recommended in his exploratory study on students' learning readiness of algebra that the mathematic curriculum need to be expanded to include pattern recognition and extension which entail strategies other than counting. Furthermore, relations between objects and numbers need to be focused while the concept of the unknown need to be introduced through varying symbols used in arithmetical expressions and sentences.

The ability to evaluate numerical expressions using patterns and relationships is fundamental if students are to move from merely exploring patterns withy finite cases to describing patterns with symbols. This is a key element of making a successful transition from arithmetic to algebraic reasoning. Pattern exploration task gives the students opportunities to apply he algebraic rules and properties to familiar numerical expressions (Lo and Tsai, 2011).

Pattern exploration tasks may contribute to the development of abilities related to problem solving, through emphasizing the analysis of particular cases, organizing data systematically, conjecturing and generalizing. The Principles and Standards for School Mathematics (NCTM, 2000) acknowledges the importance of working with numeric, geometric and pictorial patterns. Thus, instructional mathematics programs should enable students to engage in activities involving the understanding of patterns, relations and functions (Barbosa, et al., 2007).

The focus on pattern exploration is frequent in the recent approaches o the study of algebra. The search for regularities in different contexts, the use of symbols and variables that represents patterns and generalization are important components of the mathematics curriculum in many countries (DEB, 2001). Working with patterns may be considered a unifying theme of mathematics teaching, appearing in different contexts and contributing to the development of several concepts (NCTM, 2000). In this research, the use of pattern exploration tasks has the main purpose of setting the environment to analyze the impact of the use of visual strategies in generalization.

Patten generalization has become an important feature of mathematics classrooms around the world. Sometimes these activities focus purely on given numerical terms, but the use of pictorial and figural patterns is now becoming part of the standard repertoire for such generalization exercises. From a pedagogic point of view, the investigation of pictorial patterns potentially allows for a meaningful way of arriving at and exploring algebraically equivalent expressions of generality. Thus, teachers still need a tool box of pedagogical strategies which they can draw on to encourage visual engagement with the pictorial context. Also, teachers should encourage visual engagement with patterning activities presented in a pictorial context (Samson, 2012).

Awareness of Mathematical Pattern and Structure (AMPS), which generalizes across mathematical concepts, can be a reliable measure and is correlated with general mathematical understanding (Mulligan and Mitchelmore, 2009). Because the concrete experience that these objects provide, it allows

\section{Volume 6 Issue 1, January 2017}




\section{International Journal of Science and Research (IJSR) \\ ISSN (Online): 2319-7064}

Index Copernicus Value (2015): 78.96 | Impact Factor (2015): 6.391

students o have a greater understanding of mathematical concepts which becomes the basis of their conceptual mathematical knowledge.

Cockcroft (1995) summarized that mathematics teaching at all levels should include opportunities for: a) exposition by the teacher, b) discussion between teachers and students, c) discussion among students, d) appropriate practical work, e) consolidation and practice of fundamental styles and routine, and f) problem solving investigation. The idea of Cockcroft is related to the present endeavour since the nature of patterns is similar to investigation process.

\section{Conceptual Understanding and Achievement in Mathematics}

The Common Core Standards in Mathematics (CCSM) stressed the importance of conceptual understanding as a key component of mathematical expertise. One hallmark of mathematical understanding is the ability to justify, in a way appropriate to the student's mathematical maturity, why a particular mathematical statement is true or where a mathematical rule comes from (Wiggins, 2014).

In the analysis of college students' performance at Divine Word College of Vigan, Cajindos (2010) recommended that there should be a thorough explanation of the subject matter through remedial classes for students. Teachers should be inspired and should motivate the students to love the subject to strengthen the attitude towards the subject. The teachers should also be updated with the recent trends and techniques in teaching mathematics to help improve students' conceptual understanding.

Ben-Hur (2006), Steffe and Thompson (2000) posited that learning mathematical concepts involves reflection. Learning new concepts starts from sharp perception and ends in the independent ability of application. This concept is somewhat related to learning by doing on which activities may be done by students after the concept is introduced. In patterns, to learn mathematical concepts and connect the previously learned concept to new situation needs reflection.

In the study of Tsai (2010) about the epistemological relationships on students' beliefs and perceptions of constructivist learning environments where they could (1) interact and negotiate meanings with others, (2) integrate their prior knowledge and experiences with newly constructed knowledge, and (3) meaningfully control their learning activities. The main thrust of the findings drawn from this study indicates that teachers need to be very aware of students' epistemological orientation towards their mathematical knowledge and conceptual understanding to be able to complement these preferences when designing learning experiences, especially to provide constructivistbased lessons to enhance mathematics learning for students who are epistemologically constructivist oriented. The use of pattern in teaching is a constructivist - based approach, and may be of help in improving the students' conceptual understanding.

Mathematics achievement is an assessment of performance to evaluate learning after giving instruction. Lambitco, et al (2007) conducted a study to determine what factors affect students' achievement in college algebra. The results revealed that students achieve less in mathematics because it is regarded as a difficult subject and is abstract in nature. Their foundation in high school mathematics needs to be really good in order to be ready for college work. The students' mathematical ability must be high in order to obtain good performance in college algebra because learning mathematics is directly related to mathematical ability. They did not obtain the required mastery in the mathematical concepts, which they needed to possess upon entering college. The teaching methodologies related to the students achievement and mastery of mathematical concepts, thus using patterns in teaching may be appropriate for concept building.

Quimbo (2003) believed that education includes measures of the home learning environment and school inputs appropriate at the students level. Results suggest that by effectively providing basic learning materials in schools can help improve the mathematics achievement in the present endeavor as well as future life activities.

The Principles and Standards for School Mathematics recommended the use of materials in mathematical problem solving (NCTM, 2000). Japona (2000) also mentioned that teachers who teach with materials bring life to the students. It can reinforce, if properly motivated, on the students' achievement in understanding the abstract nature of mathematics. If students lack understanding of concepts, they are unlikely to construct the desired algebraic ideas. In his study on visual approach in teaching, it was revealed that visual approach was more effective in increasing g students' achievement than the traditional approach. The use of patterns is related o visual approach as a material in teaching mathematics because it includes pictures or images which will be observed by the students and discover the algebraic concept behind.

In addition, the study of Dadole (2007) on the use of structure representations revealed that the achievement scores of students who used structured representations were as good as students who did not use the faction strips. However, it has a significant effect on the retention scores of the high school students in mathematics. Patterns, like structure representation is another type of material which is used in teaching to help improve students' achievement and understanding.

Furthermore, in the study using a manipulative model conducted by Agot (2013), it showed that the use of model is better than that of the lecture - discussion method because it facilitates higher order thinking skills and provides students with high content knowledge, which is an effective and feasible option for teachers. The use of manipulative promotes high mathematics achievement among students since it can provide useful and concrete base in doing symbolic work including the equivalence of algebraic expressions. Manipulative models are like patterns. Only, his models are concrete while patterns use pictures, drawing, sketch and illustrations.

\section{Volume 6 Issue 1, January 2017




\section{International Journal of Science and Research (IJSR) \\ ISSN (Online): 2319-7064 \\ Index Copernicus Value (2015): 78.96 Impact Factor (2015): 6.391}

\section{Perceptions}

Algebra uses symbols for generalizing arithmetic. These symbols have different meanings and interpretations in different situations. According to Kieran (1992), students have different perceptions about these symbols, letters and signs. The study has revealed that the problems encountered by the students appeared to have connection with their lack of conceptual knowledge and it might have been result of teaching they experienced in learning Algebra at the secondary schooling level. In patterns, students encounter symbols and signs where perception is measured. This gives them opportunity to make connections from their previous understanding to the present.

Amoo \& Rahman (2004) said that students' participation in the instructional process is critical and their perception presents methodological challenges. The knowledge of the way the students think and perceive can aid the teacher to reflect upon and adjust the teaching strategies to enhance students' understanding and achievement. Perception is the way the student's judge, or it is an attitude to an idea or object which determines what they think feel and behave towards that idea or objects. His has something to do with a disposition to act or react in a particular way as the students respond to a situation. In this study, students were asked to give judgment about their experiences with the use of patterns.

Kershner \&Pointon (2002) pointed out that students' perceptions of appropriate practices that enable them to succeed in learning mathematics were identified through the use of interviews. Listening to the teacher was recognized as a key practice. These students noted that listening to the teacher was important when the teacher was introducing a new topic, explaining something difficult or giving instructions about a set task. They recognized that to be successful in learning mathematics there is a needed to do more than just listening to the teacher. In patterns, the students give their views about its usage and importance inside the classroom based on the given guide questions.

A study by Campbell, et al., and Haas (2002) showed that teaching strategies had influenced students' perceptions. Students with deep approaches to learning generally demonstrated a more sophisticated understanding of the learning opportunities offered to them than those students with surface approaches. When teachers focused strongly on actively engaging students and creating a supportive environment, the students with both deep and surface approaches focused only on the student - centered aspects of the class. In contrast, when traditional expository teaching methods were used exclusively, students with deep and surface approaches both focused on transmission and reproduction. In using patterns, students are deeply engaged, thus creating a student - centered classroom.

\section{Summary}

Some of the studies mentioned in the previous pages were related to the present endeavor which was about mathematical patterns as a teaching strategy. A teaching strategy influenced student's achievement, perceptions and conceptual understanding in the study of Kieran (1992); Japona (2000); Campbell, et al. and Haas (2002); Quimbo (2003); Dadole, Lambitco, et Al. (2007); Cajindos \&Tsai (2010)

A pattern uses visual imagery like geometrical shapes, numbers, symbols, graphs or diagrams. This is a powerful tool to help improve student's progress in perception and understanding as revealed in the research of The Open University (1988) \& Beigie (2011). This is a necessity in forming mathematics concept which is possible when students are encouraged to analyze and visualize mathematical situations and structures using patterns (Thorton, 2001; Schulz 2011; and Vinogradova, 2010).

Through pattern exploration task, students are given opportunities to describe patterns with symbols, determine the relation between objects and numbers, and solve problems which may guide them in the successful transition of arithmetic and patterns to algebraic reasoning (NCTM, 2000; DEB, 2001; Latonio, 2006; Barbosa, et al., 2007; and Beigie, Lo \& Tsai 2011). Thus, according to Samson (2012), pattern generalization is very important in the mathematics classroom.

\section{Results}

Table 1: The Mean and Standard Deviation of the Students' Achievement Test Scores

\begin{tabular}{|c|c|c|c|c|}
\hline & \multicolumn{2}{|c|}{ Control Group } & \multicolumn{2}{c|}{ Experimental Group } \\
\hline & Pretest & Posttest & Pretest & Posttest \\
\hline Mean & 4.29 & 8.02 & 4.03 & 9.55 \\
\hline Standard Deviation & 2.83 & 3.25 & 2.88 & 3.23 \\
\hline
\end{tabular}

Table 1 shows the mean and standard deviation of the pretest and posttest scores of the students' achievement. In the pretest, the mean of the control group is 4.29 while the experimental group is 4.03 . This means that the students had low scores since the test had 20 items. This could be because they had not remembered what had been discussed during their high school algebra. It could be observed also that the mean of the control group is a little higher than that of the experimental group. In the posttest, the adjusted mean of the control group is 8.02 while the experimental group is 9.55 . it can be seen that the experimental group has greater increase than the control group, although it has not reached $50 \%$ of the total number of items which is equivalent to 20 points. To determine if the method of teaching had an effect on the students' achievement, the analysis of covariance was used.

Furthermore, in the pretest, the standard deviation of the control group is 2.83 while that of the experimental group is 2.88. The results reveal that the students in both groups had dispersed scores. In the posttest, the standard deviation of the control group is 3.25 while that of the experimental group is 3.23. The standard deviation of the control group is greater than the experimental group and both groups have increased and the scores become more dispersed. This means that the students' scores of the control group were more heterogeneous than the experimental group because some had very low and others had high scores. Thus, the students in the 


\section{International Journal of Science and Research (IJSR) \\ ISSN (Online): 2319-7064 \\ Index Copernicus Value (2015): 78.96 | Impact Factor (2015): 6.391}

control group became more heterogeneous after the treatment.

Table 2: The Analysis of Covariance of Students' Achievement Test Scores

\begin{tabular}{|c|c|c|c|c|c|}
\hline $\begin{array}{c}\text { Source of } \\
\text { Variation }\end{array}$ & $\begin{array}{c}\text { Adjusted Sum } \\
\text { of Squares }\end{array}$ & df & $\begin{array}{c}\text { Adjusted } \\
\text { Mean Squares }\end{array}$ & $\begin{array}{c}\text { F } \\
\text { Computed }\end{array}$ & $\begin{array}{c}\text { p- } \\
\text { Value }\end{array}$ \\
\hline Treatment & 35.36 & 1 & 35.36 & 7.73 & $0.007^{*}$ \\
\hline Error Within & 269.84 & 59 & 4.57 & & \\
\hline Total & 305.2 & 60 & & & \\
\hline
\end{tabular}

*significant at $\mathrm{p}<0.05$

Table 2 presents the result of the analysis of covariance of the pretest and posttest scores of the control and experimental groups. The analysis yielded an $\mathrm{F}-$ ratio of 7.73 with a $\mathrm{P}-$ value of 0.007 , which is less than the critical value of 0.05 level of significance. This led to the rejection of the null hypothesis that there is no significant difference in the students' achievement scores as influenced by the teaching method. This implies that the use of mathematical patterns had significant influence on the students' achievement. This means that the adjusted posttest mean score of the experimental group which is 9.55 is higher than the posttest mean score of the control group which is 8.02 . This implies that using patterns in learning the concepts of functions, sequences and series had significant effect in the students' achievement scores. This finding shows that pattern could effectively provide development of conceptual understanding and supports Quimbo's (2003) study which claimed that the use of mathematical patterns, have help students improved their mathematics achievement.

Table 3: The Mean and Standard Deviation of Students' Conceptual Understanding Test Scores

\begin{tabular}{|c|c|c|c|c|}
\hline & \multicolumn{2}{|c|}{ Control Group } & \multicolumn{2}{c|}{ Experimental Group } \\
\hline & Pretest & Posttest & Pretest & Posttest \\
\hline Mean & 3.13 & 9.20 & 2.10 & 9.88 \\
\hline Standard Deviation & 2.26 & 2.01 & 1.80 & 2.68 \\
\hline
\end{tabular}

Table 3 shows the mean and standard deviation of the pretest and posttest scores of students' conceptual understanding. In the pretest, the mean of the control group is 3.13 while the experimental group is 2.10 . It can be observed that the mean score of the control group is higher than that of the experimental group. This means that the students from both groups showed only a little knowledge on the concepts of functions, sequences and series where they were expected to explain or justify their answers because the total number of points was 25 . The control group achieves only $12.5 \%$ of the total test points while the experimental group earns $8.4 \%$. In the posttest, the adjusted mean score of the control group is 9.20 while the experimental group is 9.88 . The results reveal that the experimental group had greater increase in their mean score than the control group, although it has not reached $50 \%$ of the total points. To determine if there was a significant effect of the method of teaching on the students' conceptual understanding, the ANNOVA was used for further analysis.

Meanwhile, the standard deviation of the control group is 2.26 while that of the experimental group is 1.80. This indicates that the experimental group had less dispersed scores compared to the control group. But in the posttest, the standard deviation of the control group is reduced to 2.01 while that of the experimental group, it has increased to 2.68. The standard deviation of the experimental group is greater than the control group. This means that the students' scores of the experimental group became more dispersed compared to the control group. The experimental group became more heterogeneous after the treatment.

Table 4: The Analysis of Covariance for Students' Conceptual Understanding Test Scores

\begin{tabular}{|c|c|c|c|c|c|}
\hline $\begin{array}{c}\text { Source of } \\
\text { Variation }\end{array}$ & $\begin{array}{c}\text { Adjusted Sum } \\
\text { of Squares }\end{array}$ & DF & $\begin{array}{c}\text { Adjusted } \\
\text { Mean Squares }\end{array}$ & $\begin{array}{c}\text { F- } \\
\text { computed }\end{array}$ & $\begin{array}{c}p- \\
\text { value }\end{array}$ \\
\hline Treatment & 13.04 & 1 & 13.04 & 4.27 & 0.043 \\
\hline Error & 180.04 & 59 & 3.05 & & \\
\hline Within & & & & & \\
\hline Total & 193.08 & 60 & & & \\
\hline
\end{tabular}

Table 4 shows the result of the analysis of covariance of the pretest and posttest scores of the control and experimental groups. The analysis yielded an $\mathrm{F}$ - ratio of 4.27 with a $\mathrm{P}$ value of 0.043 , which is less than 0.05 level of significance. This led to the rejection of the null hypothesis that there is no significant difference in the students' conceptual understanding as influenced by the teaching method. This implies that the use of mathematical patterns had influenced the students' conceptual understanding on the topics included in the study. This implies further that working with patterns was a good method of teaching in mathematics because the students' scores in the experimental group had improved. This means that the posttest conceptual understanding of the experimental group of 9.88 is higher than the control group with a mean score of 9.20. This explains that the use of mathematical patterns in class had helped developed a good conceptual understanding of the students on the lesson discussed.

Student's Responses to the Question "How will you describe your experience using mathematical patterns?"

Learning mathematics through mathematical patterns is done through investigation, which means that students will observe and think of the connections between numbers, pictures and figures. Based from these observations, the students will develop a model which represents the whole problem. The following were the students' learning experiences:

\section{a.) Math is fun}

Learning mathematics for many is neither easy nor fun. However, learning mathematics with the use of mathematical patterns caught the students' interest. Thus, the students find joy in doing problem solving.

- It is enjoying.

- I am just like playing while making connections of the data provided.

b) Math needs tool.

Imagery is a powerful tool for perception and understanding. The use of mathematical patterns used images and figures that help bridge the concrete nature of mathematics to abstract. This means that the students learn mathematics slowly through self-observation, discovery and analysis. It 


\section{International Journal of Science and Research (IJSR) \\ ISSN (Online): 2319-7064}

Index Copernicus Value (2015): 78.96 Impact Factor (2015): 6.391

helps me think well because the classroom atmosphere is silent. At first I just laugh because there is less talk from the instructor but it helps me understand the discussion. It is more or self-discovery and analysis. But I realize that there is a great advantage in thinking by myself and be able to share my own understanding to my seatmate.

The students enjoyed the activity with the use of patterns and enable them to think deeply because they were given time to think and analyze. This implies that the use of patterns was really effective in improving students' performance.

Table 5: Students' Responses to the Question "Do you think the use of mathematical patterns would be of help to other

\begin{tabular}{|l|l|l|}
\multicolumn{3}{|c}{ learners? Why?" } \\
\hline Responses & Frequency & Percentage \\
\hline Yes & 20 & 64.52 \\
\hline No & 11 & 35.48 \\
\hline Total & 31 & 100 \\
\hline
\end{tabular}

Table 5 presents the students' belief in the usefulness of mathematical patterns in learning mathematics for other learners. More than sixty percent $(64.52 \%)$ of the total participants believed that mathematical patterns were of help to other learners while thirty five percent $(35.48 \%)$ did not believe that it was useful to other learners. This indicates that majority of the participants believed that the use of mathematical patterns would be of help to other learners.

The use of mathematical patterns was found effective in improving students' performance. It was recommended to other learners because it is helpful in developing new skills which is useful in the formulation of new concepts and ideas.

\section{a) Critical Thinking}

- The use of mathematical patterns helped develop students' critical thinking and analysis of practical problems. And given enough time to perform the task, students may be able to perform better.

- Yes, because it allows us to improve our own thinking by ourselves.

- Yes, but maybe if they are given enough time. The time is very short.

\section{b) Conceptual Understanding}

- Mathematical patterns helped improved the students' conceptual understanding. Conceptual understanding is the key component of mathematical expertise. This is the ability to justify, in a way appropriate to the students' mathematical maturity.

- Yes, because they may learn the way I learn and it might be easier for them to understand the topic.

- Yes, but not sure, students are different.

- Yes, because our previous understanding from high school was activated and able to connect from it.

- Yes, because the basic was used to help us understand the concept of algebra.

- Yes, because it might be difficult for us, but for them it would be easier and they can learn better.

- Yes because we are allowed to explain our ideas and present to our classmates.
However, there were some who did not believe in the ability of mathematical patterns to help other learners because of its content difficulty of the activity and due to less classroom discussion.

- No, because it is very difficult for a learning to take place without the constant talk and discussion of the teacher about the lesson.

- No, because I don't even get it myself how much more the other students.

- No, because we are expected to answer even if we don't have any discussion yet.

Majority of the students' responses indicated that the use of patterns was of help to other learners because it was also of help to them as shown in table 7. Thus, the use of mathematical patterns, which allowed students to become part of the learning process, was commendable to other learners.

\section{Findings}

Based on the analysis, the following are the findings:

a) There is a significant difference in the students' achievement and conceptual understanding scores as influenced by the teaching method which is the use of mathematical patterns. The students in the experimental group who were taught using the mathematical patterns performed better than the control group where lecture discussion method was used.

b) The students in the experimental group find mathematical patterns enjoyable and interesting, which allows them to develop their critical thinking and make mathematics learning easier for them. In addition, students believed that the use of mathematical patterns id helpful and useful in understanding mathematical concepts not only for themselves but also for other students.

\section{Conclusions and Recommendations}

This study concluded that the use of mathematical patterns have caused better students' achievement and conceptual understanding than the lecture - discussion method and it is an acceptable method of learning by learners.

The researcher then recommends that mathematics teachers may use mathematical patterns in their classes to help students improve achievement and develop conceptual understanding in mathematics even for pre-school, elementary and secondary level. School administrators may motivate mathematics teachers to use mathematical patterns for classroom instruction especially in pre-school, elementary and secondary levels where all foundations of mathematics were first discussed. School administrators should expose mathematics teachers to the use of mathematical patterns through in-service training and similar studies may be conducted by other researchers who wish to investigate the use of mathematical patterns in the classroom considering other factors like student's mental ability, academic level, other disciplines and increase of time span of the study. 


\section{International Journal of Science and Research (IJSR) \\ ISSN (Online): 2319-7064}

Index Copernicus Value (2015): 78.96 Impact Factor (2015): 6.391

\section{References}

[1] Agot, M. V. (2013). Manipulative Models and Mathematics Achievement in Elementary Algebra. (Unpublished Master Thesis, Mindanao University of Science and Technology, Cagayan de Oro City).

[2] Alfieri, L. Brooks, P. J., Aldrich, N.J., \& Tenenbaum, H. R. (2011). Does Discovery - Based Instruction Enhance Learning? Journal of Educational Psychology. 103 (1) 1 -8 .

[3] Amoo, S. A., \& Rahman, M. A., (2004). Secondary School Students' Attitude of Learning Mathematics in the World of Information Technology. Implication for Mathematics Teachers and Teacher Preparation. 178 182.

[4] Barbosa, A. Valle, I. Palhares, P. (2007). Pattern Tasks: Thinking Process used by 6th Grade Students. Retrieved last June 1, 2014 from www.cielo.org.mx/pdf/relime/v15n3/v15n392.pdf.

[5] Beigie, D. (2011). Leap from Patterns. Mathematics Teaching in the Middle School. Vol. 16. No. 6

[6] Ben-Hur, M. (2006). Concept - rich Mathematics Instruction, Alexandria, Virginia USA: Association for Supervision and Curriculum Development.

[7] Borrows, H. (1985). Retrieved last October 8, 2014 from www.en.wikipedia.org/wiki/Howard_Borrows.

[8] Bruner, J. (1996). Toward a Theory of Instruction. Cambridge, MA: Harvard University Press.

[9] Cajindos, R. (2010). Analysis of the Performance in Trigonometry of the First Year College Students of Divine Word College of Vigan.

[10] Campbell, J. et. al. (2010). Students' Perceptions of Teaching and Learning: The Influence of Students' Approaches to Learning and Teachers' Approaches to Teaching.

[11] Cockcroft, W. H. (1995) Mathematics Counts. Her Majesty Service Office (HMSO), London. Retrieved last June 2, 2014 from www.unescoiicba.org/EnglishGirlsEducation/AllArticles/SecondaryE d/Student'sMathematicsSelf-

ConceptandMotivationtoLearnMathematics.pdf

[12] Dadole, A. D. (2007). Using Structured Representations - Fraction Strips in Problem Solving: Its Influence on the Mathematics Performance of High School Students. (Unpublished Master Thesis, Mindanao Polytechnic State College, Cagayan de Oro City.)

[13]Departamento do Ensino Basico (DEB). (2011). Curriculo Nacional do Ensino Basico. Competencias Essenciais. Retrieved from www.academia.edu/1425435/Patterns_and_generalizatio $\mathrm{n}$ the_infuence_of_visual_strategies

[14] Dewey, J. (1938). Experience and Education. Toronto: Collier-MacMillan Canada Ltd.

[15]English, L. (2009). Promoting the Development of Young Children's Mathematical and Analogical Reasoning. Mahwah, NJ:Erlbaum.

[16] Galvez, L. (2009). Tools in Teaching Basic Math. Institute of Mathematics University of the Philippines (Diliman).
[17]Fi, C. D. and Degner, K. M. (2012). Teaching through Problem Solving. Mathematics Teacher. Volume 105, No. 6.

[18] Japona, F. Jr. (2000). Visual Approach in Teaching Selected Topics in High School Algebra: Its Effect on Students' Achievement and Attitudes Towards Mathematics. (Unpublished Master Thesis, Mindanao University of Science and Technology, Cagayan de Oro City.)

[19] Jonassen, D. (1999). Designing Constructivist Learning Environment. Pennsylvania State University.

[20]Kieran, C., \& Chalouh, L. (1993). Pre-Algebra: The Transition from Arithmetic to Algebra. Research Ideas for the Classroom: Middle Grades Mathematics.

[21] Kershner, R. \& Pointon, P. (2000). Children's Views of the Primary Classroom as an Environment for Working and Learning. Research in Education, 64, 64-67.

[22]Latonio, R. (2006). An Exploratory Study in Determining Algebra Learning Readiness Levels of Randomly Selected Grade Three and Grade Four Students of a Private Elementary School in Central Visayas.

[23] Lambitco, B. et. al. (2007). Determinants of Students' Performance in Algebra. TIP-Manila Research Journal Vol. 4, No. 1 Retrieved from http://ejournals.ph/index.php?journal=hdjskandkjahewku hri\&page $=$ article\&op $=$ viewArticle \&path $\% 5 \mathrm{~B} \% 5 \mathrm{D}=324$ 2.

[24]Lo, J. and Tsai, F. (2011). Taiwanese Arithmetic and Algebra. Mathematics Teaching in the Middle School. Vol. 16. No. 7.

[25] Mulligan, J. and Mitchelmore, M. (2009). Awareness of Pattern and Structure in Early Mathematical Development. Mathematics Education Research Journal. Vol. 21. No. 2.

[26] National Council for Teachers of Mathematics (NCTM). (2000). Principles and Standards for School Mathematics. Reston, VA: NCTM.

[27] National Mathematics Advisory Panel. (2008). Foundations for Success: the Final Report of the National Mathematics Advisory Panel. Washington, DC: US Department of Education.

[28] Papert, S. (1960) Constructionism. Retrieved ast May 20, 2014 from http://www.cs.tcd.ie/disciplines/information_systems/crit e/crite_web/lpr/teaching/constructionism.html.

[29] Piaget, J. (1960). Theory of Cognitive Development. Retrieved last June 1, 2014 from http://en.wikipedia.org/wiki/Jean_Piaget.

[30] Quimbo, S. A. (2003). Explaining Math and Science Achievement of Public School Children in the Philippines. Volume 40, Number 2. Retrieved last January $7, \quad 2014$ from http://pre.econ.upd.edu.ph/index.php/pre/article/view/21

[31] Quinn, R. (2005). A Constructivist Lesson to Introduce Arithmetic Sequences with Patterns. Australian Mathematics Teacher. Vol. 61. NO. 4 Pg. 18-21.

[32] Samson, D. (2012). Encouraging Meaningful Engagement with Pictorial Patterning Tasks. Australian Mathematics Teachers. Vol. 68 No. 2 Pg. 4 - 10. 
[33] Schulz, J. (2011). Promoting Teaching as Design in Elementary: Exploring the Potential of Curriculum Support Materials. Retrieved on March 16, 2012 from http://scholar.lib.vt.edu/theses/available/etd-11212011$164859 /$

[34] Tsai, C. (2010). Relationships between Student Scientific Epistemological Beliefs and Perceptions of Constructivist Learning Environments.

[35] The Open University. (2014). Using Visualization in Mathematics Teaching. Retrieved on May 8, 2014 from http://www.open.edu/openlearn/education/usingvisualisation-maths-teaching/content-section-3

[36] Thornton, S. (2001). A Picture is Worth a Thousand Words: Why Visual Thinking?. Retrieved last May 17, 2014 from math.unipa.it/ grim/Athornton251.pdf

[37] Vinogradova, N. (2011). Let's Cut a Square. Mathematics Teaching in the Middle School. Vol.16. No. 6.

[38] Von Glasersfeld, E. (1989). Constructivism in Education. Retrieved last September 24, 2014 from www.univie..ac.al/constructivism/EvG/papers/14.pdf.

[39] Vygotsky, L. (1978). Mind in Society: The Development of Higher Psychological process. London: Harvard University Press.

[40] Waters, J. (2004). Mathematical Patterning in Early Childhood Settings. In I. Putt, R. Faragher McLean (Eds.). Mathematics Education for the Third Millennium: Towards 2010. Townsville, Australia: MERGA.

[41] Wiggins, G. 2014. Conceptual Understanding in Mathematics. Updated last April 23, 2014. Retrieved last January $\quad 8, \quad 2015$ from https:/grantwiggins.wordpress.com/2014/04/23/concept ual-understanding-in-mathematics/

[42] Witzel, A. (2003). The Concrete - Pictorial - Abstract Approach. Retrieved last May 15, 2014 from www. Loganschools.org/mathframework/CPA.pdf

\section{Author Profile}

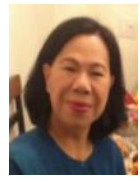

Christina V. Maglipong is a Professor of the Department of Mathematics Education of the College of Science and Technology Education of the University of Science and Technology of Southern Philippines. She has been teaching mathematics subjects the institution for more than 30 years. Currently she is the Director of the Quality Assurance and Accreditation Services (QUAAS) and been travelling to the different regions in the country to accredit programs of state universities and colleges programs to ensure quality of inputs and aimed to improve the programs current status. Aside from her work as a director and professor, she has devoted herself making researchers in the field of mathematics education, presented this research outputs in the local and international fora and published articles in reputable local and international journals.

Jean L. Bongolto finished her Master of Science in Teaching Mathematics at the University of Science and Technology of Southern Philippines. At present she is a fulltime faculty member of the St. Rita's College of Balingasag, Balingasag, Misamis Oriental. She is also active in conducting research studies in mathematics education since her early years as a college instructor. 